\title{
INTERFERENCE THE MATERNALLY DERIVED ANTIBODY AND THE COMMERCIAL BURSAL LIVE VACCINES AT BROILER CHICKENS
}

MAAMON AL AMIR and ANOUAR. ALOMAR

\section{ABSTRACT}

This work aims to studying the effects of maternal derived antibodies against the live vaccines of infectious bursal disease for the chicks, and serological estimation

Received at: 31/3/2013 for interference between the maternal derived antibodies and the Gomboro live vaccines which are given in the early age, as well as achieving the best vaccination program to control the disease. Group of chicks were taken from elderly parents and this was divided into five groups 24 one day old chicks/group. One of these groups was raised as a negative control, and the other four groups were given various Gomboro live vaccination (hot and intermediate vaccines) at different ages. The levels of antibodies were examined weekly, which was produced from the weekly vaccinated birds, were examined. The high levels of maternal derived antibodies have affected the given vaccines, and they interfere with the maternal derived antibodies when using the live Gomboro vaccines.

Key words: Maternal antibody, live vaccines, broiler chickens

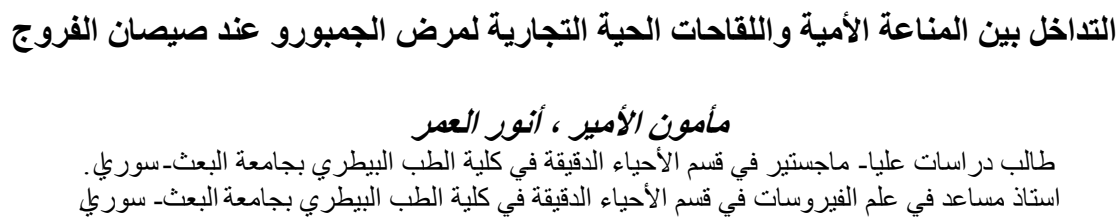

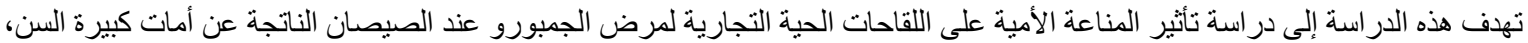

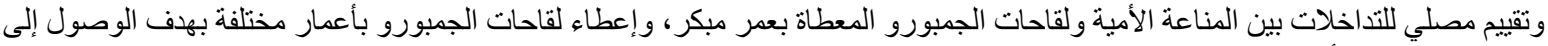
برنامج التحصين الأمثل للسبطرة على المرض.

أجريت الدر اسة على مجمو عة من صيصان أخذت من أمات متقدمة في السن وقسمت إلى خمس مجمو عات كل مجمو عة تتألف من

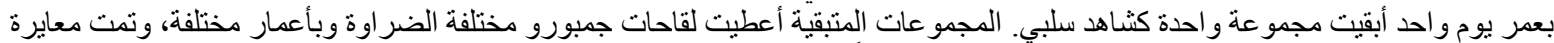

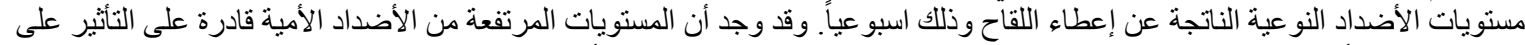

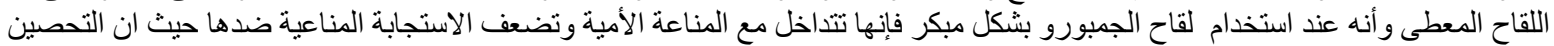

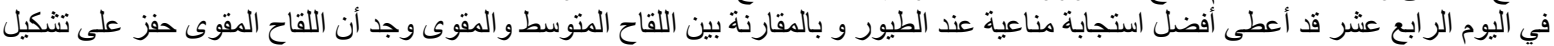

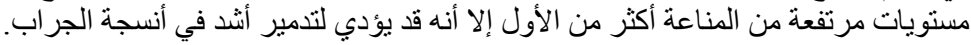

\section{المقدمـــة \\ INTRODUCTION}

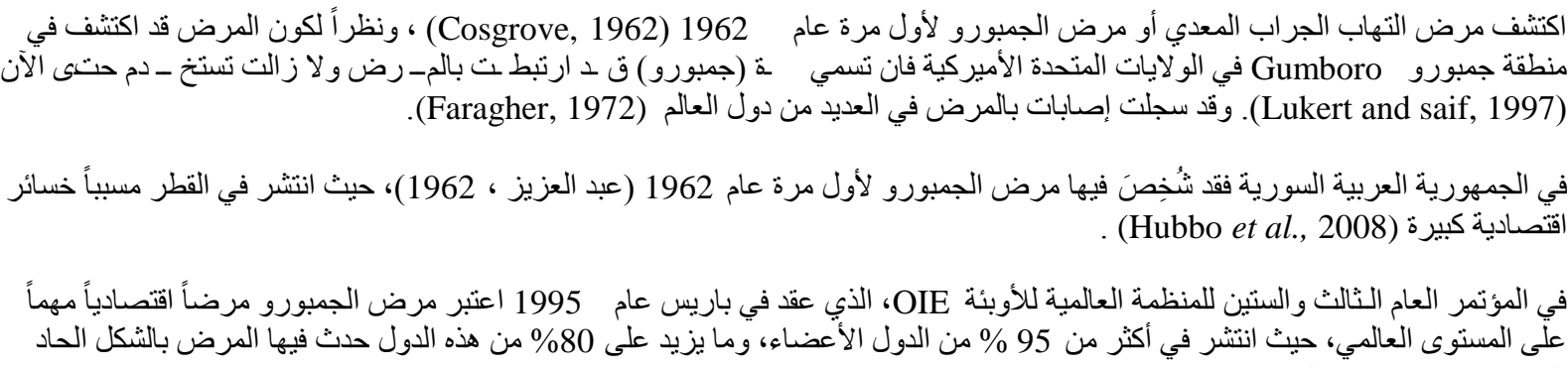

(Eterradossi, 1995)

ينتمي العامل المسبب لمرض الجمبورو إلى عائلة بيرنا Carter et al., 2005) Birnaviridae)، و هي تضم ثناثة أجناس رئيسة، و احد منها فقط

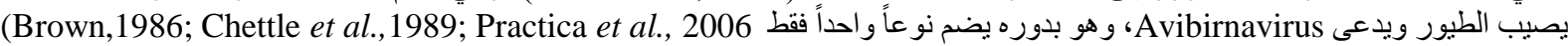

; Pedro et al., 2008) 


\section{Assiut Vet. Med. J. Vol. 59 No. 137 April 2013}

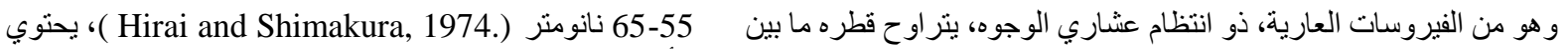

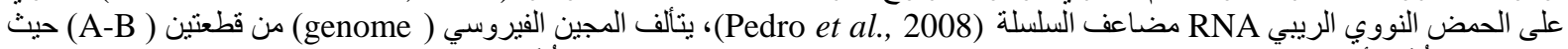

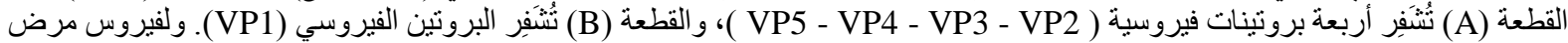

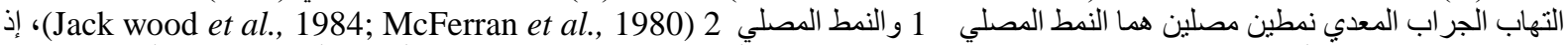

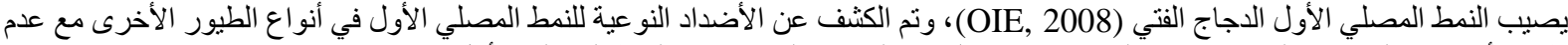

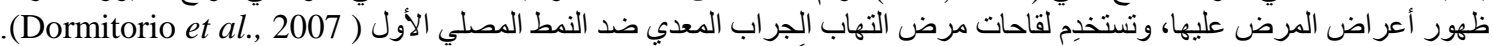

النمط المصلي الأول Serotype1، يصيب الدجاج ويسبب تثبيطاً للجهاز المناعي فيها، ويضم ثلاث عتر اتل (Patricia et al., 2006):

آـ العترات الكلاسيكية Classic IBDV Strain: وتتنمي إليها العترة الكلاسيكية الضارية Virulent Classic IBDV التي تنتشر في أنحاء مختلفة العالم (Lojkic et al., 2008 ; OIE, 2008).

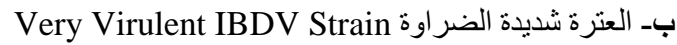
ج- العترة المتغايرة Variant IBDV Strain

أما النمط المصلي الثاني Serotype 2 فيُعد مسبباً للمرض في الدجاج الرومي (Ismail et al., 1988)، وهو غير ممرض للاجاج، حيث لوحظ

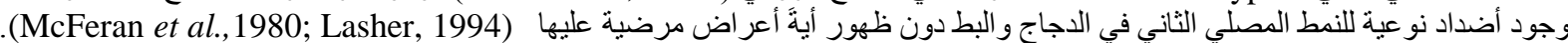
إذ يُمكن التفريق بين هذين النمطين المصليين باستخدام اختبار التعادل الفيروسي (Neutralization Test Virus).

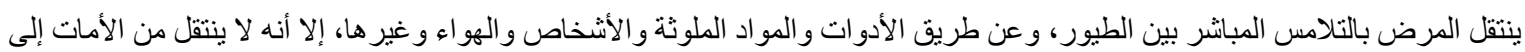

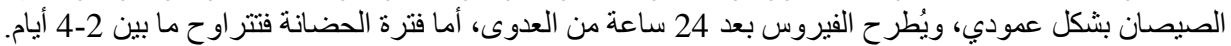

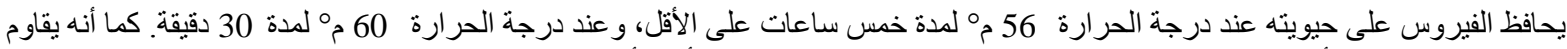

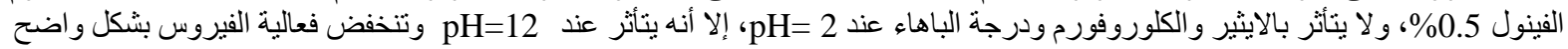
عند معاملته بالفور مالين 5 \% لمدة 6 ساعات (Benton et al., 1967; Rosenberger et al., 1989).

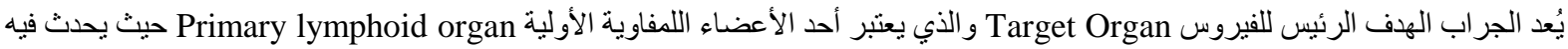

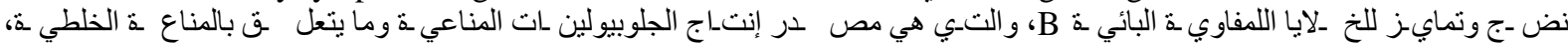
(Tanimura and Sharma, 1997)

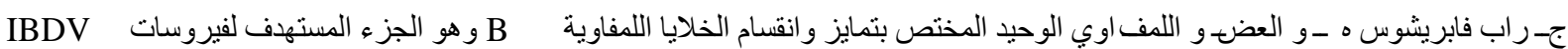
.(Dohms et al., 1988; Sivandan and Maheswaran, 1980; Rodenberg et al., 1994)

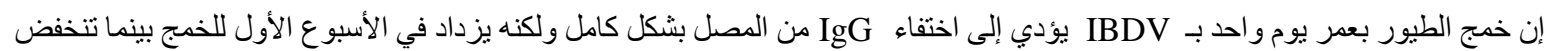
مستويات IgM معنويا للخمج وبغض النظر عن وقت الخمج (Hirai et al., 1974).

إن التثيط المناعي الناتج عن الإصابة بـ IBD يكون مسؤو لا عن مضاعفات الإصابة بأخماج حقلية أخرى (Dohms and Saif, 1984).

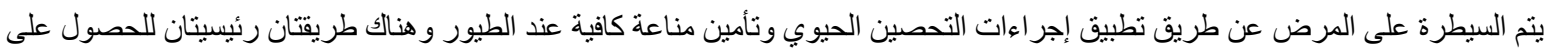

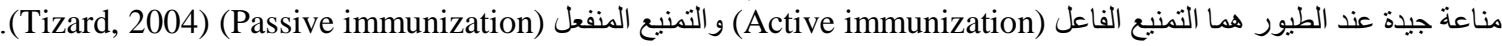

يوجد نو عان من هذه اللقاحات هما الأكثر توفر اللسيطرة على المرض و هي إما لقاحات حية مضعفة Live attenuated vaccine أو لقاحات خاملة OIE, 2008; Thornton and Pattison et al., 1975) Oil-emulation adjuvante vaccine.

تحضر اللقاحات الحية من عتر ات حقلية للفيروس مضعفة إنهات على المزارع الخلوية أو على أجنة بيض الدجاج وتختلف هذه اللقاحات فيما بينها تبعا

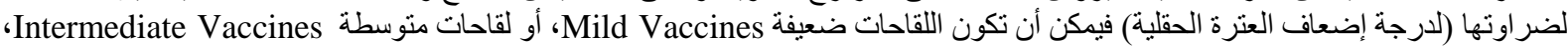

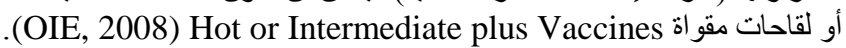

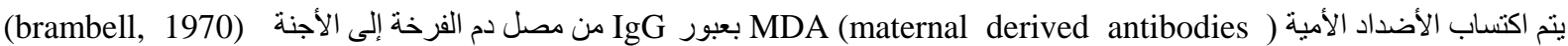

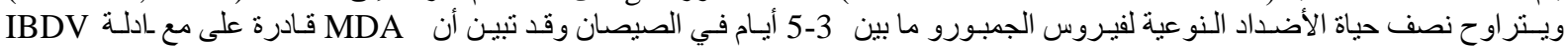

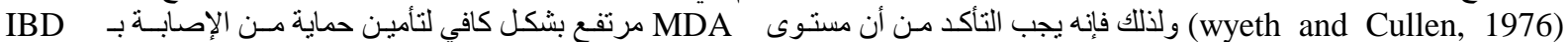
خصوصا خلال الاسابيع 2-3 الأولى من العمر قبل التحصين لا IBDoya et al., 1992)

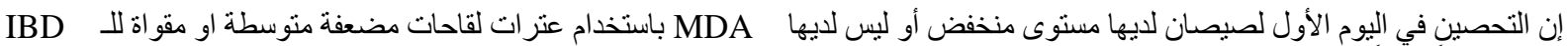

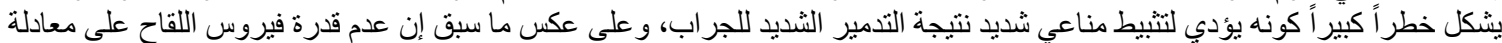

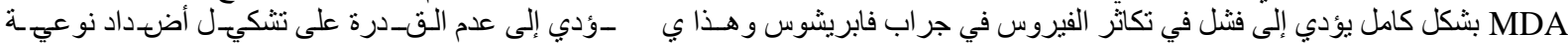
(Hair-Bejo et al., 2004)

إن وقت التحصين، ونوع اللقاح، و الأضداد الأمية عند الصيصان، وتحدي و إمر اضية الـ IBDV الحقلية هي عو امل مهم لتحديد فعالية (نجاعة)

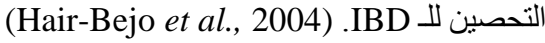




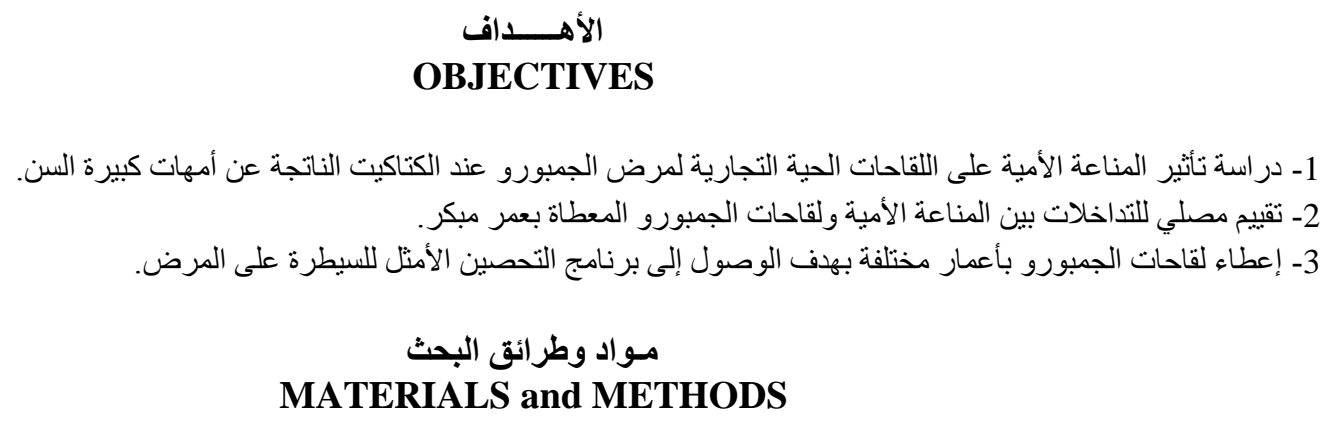

ـ اللقاحات Vaccines

استخدمت لقاحات حية منوسطة intermediate vaccines ولقاحات مقو اة Intermediate plus vaacines كما يلي:

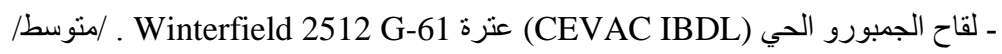

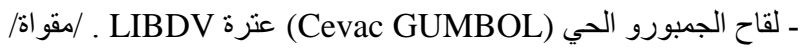
مع التنويه إلى أن كل المجمو عات لم تحصن بأي لقاح ضد أي مرض آخر عدا لقاح الجمبورو حسب النوع و المو عد المحدد في التجربة.

الطرق Methods كان عدد عند بداية التجربة 120 صوص في اليوم الأول من العمر (والتي أخذت من أمهات كبيرة في العمر ) قسمت إلى خمس مجمو عات ( 24

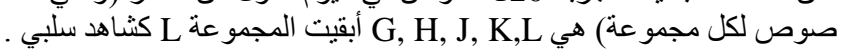
وكانت مو اعيد التحصين في جميع المجمو عات كما هو موضح في الجداول رقم 1 : الجدول رقم 1: يوضح مو عد التحصين ونوع اللقاح المستخدم

\begin{tabular}{|c|c|c|}
\hline 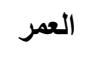 & نوع اللقاح & المجموعة \\
\hline 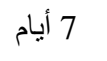 & متوسط Intermediate & $\mathbf{G}$ \\
\hline 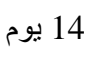 & مقوى Intermediate plus & $\mathbf{H}$ \\
\hline 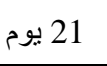 & متوسط Intermediate & $\mathbf{J}$ \\
\hline 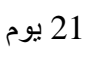 & مقوى Intermediate plus & $\mathbf{K}$ \\
\hline- & شـاهد سلبي & $\mathbf{L}$ \\
\hline
\end{tabular}

ـ العينات Samples

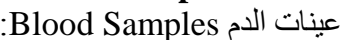

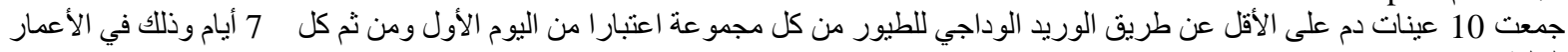

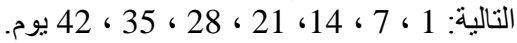
وذلك لتتبع مستويات المناعة الأمية و المناعة المشكلة نتيجة إعطاء اللقاح. وضعت عينات الدم في أنابيب معقمة بشكل مائل على سطح مستوي لتسريع عملية تجلط الدم و المساعدة في انفصال المصل ثم تم تثفيل العينات بسر عة 2000 د/د لمدة 10 دقائق.

حفظت عينات المصل بعد توزيعها إلى أحجام صغيرة بدرجة حرارة -20 درجة مئوية لتتم معايرة الأجسام المناعية المضادة لاحقاً. طريقة التحصين Vaccination أعطي اللقاح عن طرين التصني التقير بالأف حيث تمت إذابة محتويات عبوة اللقاح المجفد بالمذيب الخاص به وذلك حسب تعليمات الثركة المصنعة. 
المقايسة المناعية بالأنزيم المرتبط غير المباشرة Indirect Enzyme-Linked Immunosorbent Assay:

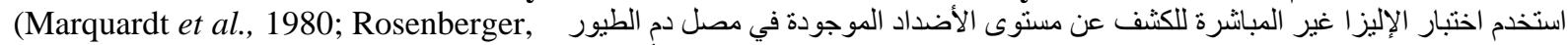
1989; OIE, 2008) وذلك باستخدام مجمو عتان تشخيصيتان من شركة IDEXX الأمريكية (Serial No.:09260-EE206).

وتتألف المجمو عة التشخيصية الواحدة لاختبار الإليزا غير المباشرة من:

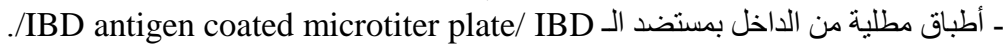

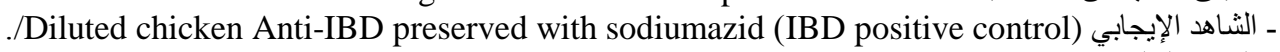
ـ الشاهد السلبي Negative controle. ـ محلول الاقتران المرتبط بالأنزيم Horseradish Peroxidase Conjugate: Anti-Chicken (Goat).

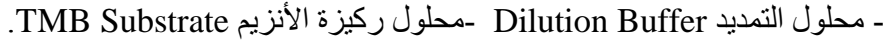
- محلول إيقاف التفاعل Stop Solution.

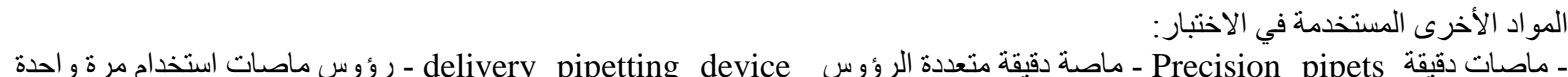
disposable pipte tips - جهاز قارئ الإليز اللطبق ذو 96 حفرة 96-well plate reader نوع (BIO-TEK INSTRUMENT, INC) و (Serial No. 186696)

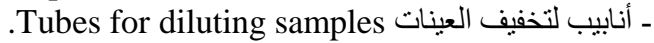
ـ ماء منزوع الثوارد لإجر أباء عملية غسيل الحفر.

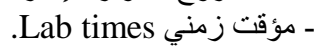

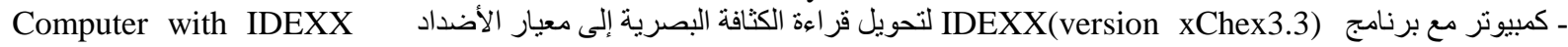
.Software program

1 ميكروليتر و أضيف إليه 500 ميكروليتر من محلول التمديد

: Preparation serum samples تحضير عينات المصل للاختبار

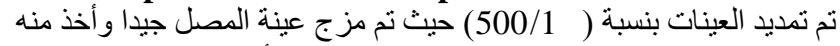
Dilution Buffer

تريقة العمل:

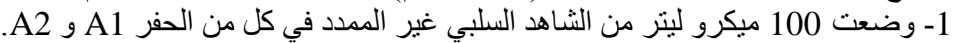

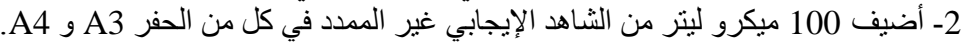

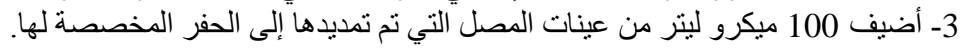

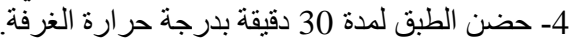

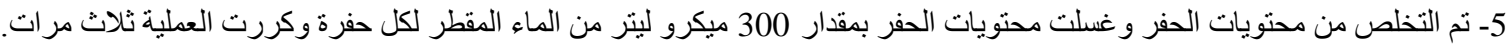

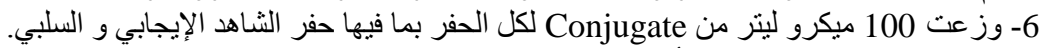

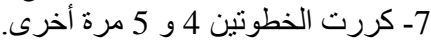

8- وزعت 100 ميكرو ليتر من محلو مرة أخرى الركيزة TMB Substrate

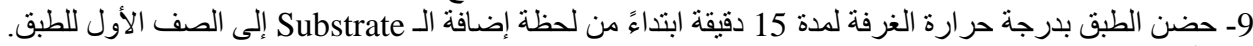

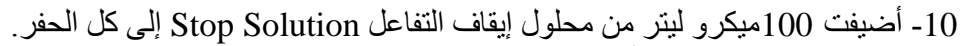

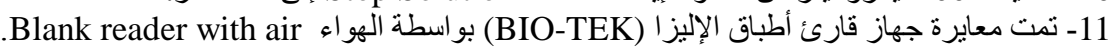

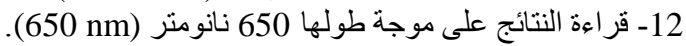

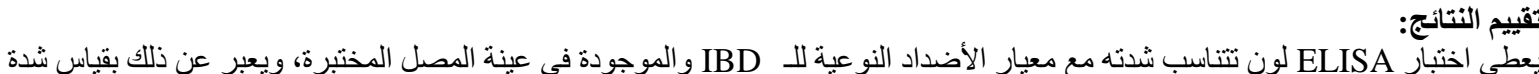

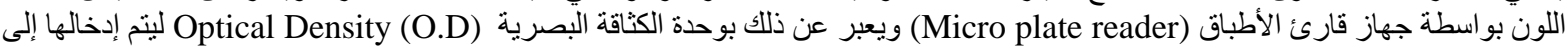

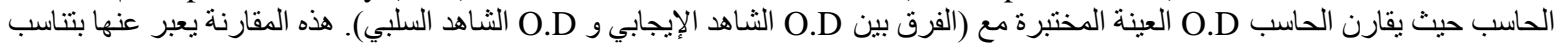

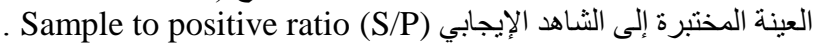

وحتى تكون نتائج العمل صحيحة يجب أن يكون الفرق بين متوسط الثـاهد الإيجابي و متوسط الثـاهد السلبي (PC وأن يكون متوسط امتصاصية الثناهد السلبي أقل من (0.150).

و عندما تكون قيمة التناسب S/P للعينة المختبرة أقل أو يساوي (0.20) تعتبر العادير العينة سلبية، و عندما تكون قيمة تناسب S/P للعينة المختبرة أكبر من

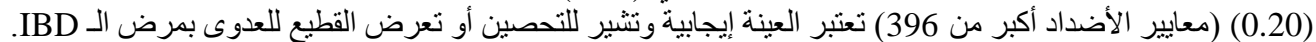
تم حساب معايير الأضداد بواسطة الحاسوب وفق طريقة: (Synder and Marquardt, 1989; De Herdt et al., 2000) .

Negative control mean $\left(\bar{X}_{\mathrm{NC}}\right)$

$\frac{\text { Well } A 1 A(650)+\text { Well } A 2 A(650)}{2}=\bar{X} \mathrm{NC}$


Positive control mean $\left(\bar{X}_{\mathrm{PC}}\right)$

$$
\begin{aligned}
\mathrm{PC} \bar{x} & =\frac{\text { Well } A 3 A(650)+\text { Well } A 4 A(650)}{{ }^{2}} \\
S / p \text { ratio } & S / p=\frac{\text { Sample Mean }-N C \bar{x}}{\mathrm{PC} \bar{x}-\mathrm{NC} \bar{x}}
\end{aligned}
$$

Titer-relates $S / p$ at a 1:500 dilution to an endpoint titer :

$$
\log _{10} \text { Titer }=1.09\left(\log _{10} s / p\right)+3.36
$$

$$
\text { التحليل الإحصائي }
$$

\section{Statistical analysis}

أجري التحليل الإحصائي للنتائج على برنامج 1998 Statistix وباستخدام تحليل التباين لمعيار واحد وهو One Way ANOVA وذللك للتقصي عن وجود فروق معنوية في قيم المتوسطات الحسابية لمعايير الأضداد.

\begin{tabular}{|c|c|c|c|c|c|}
\hline \multicolumn{5}{|c|}{ ELISA titer $($ Mean \pm SD) } & \multirow{2}{*}{ بالأيام } \\
\hline L المجموعة L & المجموعة K & المجموعة J & المجموعة H & G المجموعة G & \\
\hline $5064.25 \pm 1505.81$ & $5064.25 \pm 1505.81$ & $5064.25 \pm 1505.81$ & $5064.25 \pm 1505.81$ & $5064.25 \pm 1505.81$ & 1 \\
\hline $1189.7 \pm 192.06 \mathrm{~ns}$ & $1182 \pm 291.28 \mathrm{~ns}$ & $1979.3 \pm 205.46 \mathrm{~ns}$ & $1522 \pm 204.53 \mathrm{~ns}$ & $1881.8 \pm 271.69 \mathrm{~ns}$ & 7 \\
\hline $156.7 \pm 42.95 \mathrm{~b}$ & $679.1 \pm 155.85$ a & $538.8 \pm 95.48$ ab & $467.7 \pm 155.46 \mathrm{ab}$ & $459.7 \pm 112.13 \mathrm{ab}$ & 14 \\
\hline $101.5 \pm 41.81 \mathrm{~b}$ & $57.7 \pm 25.15 \mathrm{~b}$ & $609.7 \pm 94.64 \mathrm{a}$ & $222.4 \pm 78.18 b$ & $28.6 \pm 12.81 \mathrm{~b}$ & 21 \\
\hline $37.54 \pm 36.54 b$ & $84.7 \pm 62.47 b$ & $1 \pm 0 \mathrm{~b}$ & $1239 \pm 226.44$ a & $1 \pm 0 \mathrm{~b}$ & 28 \\
\hline $1 \pm 0 b$ & $1579.4 \pm 174.44$ a & $1387.8 \pm 256.50$ a & $938.8 \pm 192.19$ a & $1 \pm 0 b$ & 35 \\
\hline $1 \pm 0 c$ & $1717.4 \pm 312.85 a$ & $1027.3 \pm 112.79 b$ & $1388 \pm 173.10 \mathrm{ab}$ & $1 \pm 0 \mathrm{c}$ & 42 \\
\hline
\end{tabular}

\section{النتائج \\ RESULTS}

كانت معايير الأضداد للمجموعات كما هو موضح في الجدول رقم (2).

جدول رقم 2: يوضح نتائج معايير الأضداد للمجموعات خلال التجربة

معايير الأضداد للجمو عات خلال التجربة (المتوسط الحسابي 土 الانحر اف المعياري)

\section{المناقثة}

\section{DISCUSSION}

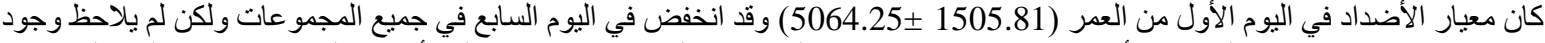

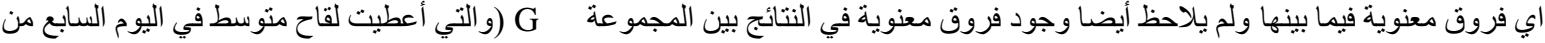

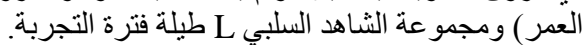
المجمو عة H والتي أعطيت لقاح مقوى في اليوم 14 من العمر لوحظ وجود ارتفاع معنوي في معيار الأضداد في اليوم 42 مقارنة بمجموعة الثاهد السلبي. المجمو عة J والتي أعطيت لقاح متوسط في اليوم 21 من العئ العمر لوحظ أيضا ارتفاع معنوي في معيار الأضداد في اليوم 42 من العمر مقارنة

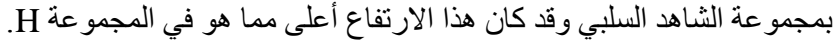

المجمو عة K والتي أعطيت لقاح مقوى في اليوم 21 من العي العمر لوحظ أيضا ارتفاع معنوي في معيار الأضداد في اليوم 42 من العمر مقارنة

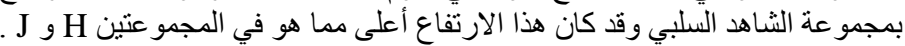




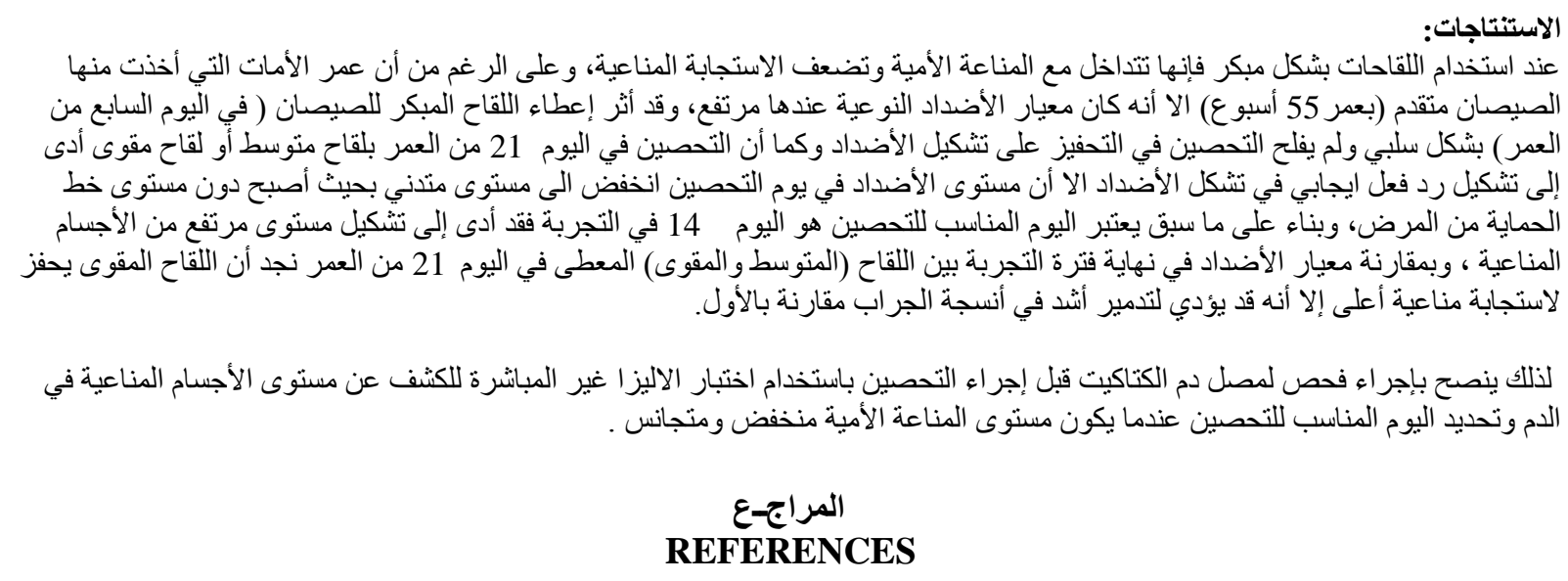

$$
\begin{aligned}
& \text { عبد العزيز، فهيم. 1996. در اسة الو اقع الوبائي لمرض التهاب جر اب فابريشيوس في مز ارع ر عاية الفروج. مجلة جامعة تشرين للار اسات }
\end{aligned}
$$

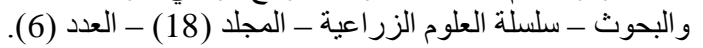

Benton, W.J.; Cover, MS. and Rosenberger, J.K. (1967): Studies on the transmission of the infectious bursal agent (IBA) of chickens. Avian DIS 11: 430- 438.

Brambell, F.W.R. (1970): The transmission of passive immunity from mother to young. Frontiers of Biology, 18: $20-41$.

Brown, F. (1986): The classification and nomenclature of viruses: Summary of results of meetings of the International Committee on Taxonomy of Viruses in Sendai. Intervirology 25:141-143.

Carter, G.R.; Wise, D.J. and Flores, E.F. (2005): Birnaviridae: In Virology. Cited by www.ivis.org.

Dohms, J.E. and Jaeger, J.S. (1988): The effect of infectious bursal disease virus infection on local and systemic antibody responses following infection of 3-week-old broiler chickens. Avian Dis. 32: 632-640.

Dohms, JE. and Saif, YM. (1984): Criteria for evaluating immunosuppression. Avian Dis. 28:305-310.

DormitorioA, T.V.; GiambroneAC, J.J.; GuoA, K. and JackwoodB. D.J. (2007): Molecular and Phenotypic Characterization of Infectious Bursal Disease Virus Isolates. Avian Diseases 51(2):597-600

Eterradossi, N. (1995): Progress in the diagnosis and prophylaxis of infectious bursal disease in poultry.Comprehensive reports on technical items presented to the international committee or to regional commissions; (pp75-82): Paris: OIE.

Faragher, J.T. (1972): Infectious bursal disease of chicken. Vet. Bull. 142: 361-396.

Hair-Bejo, M.; Ng, M.K. and Ng, H.Y. (2004): Day Old Vaccination Against Infectious Bursal Disease in Broiler Chickens Poultry Science 3 (2): 124-128, 2004.

Hirai, K. and Shimakura, S. (1974): Structure of infection bursal disease virus. J Virol 14: 957 -964.

Hirai, K.; Shimakura, S.; Kawamoto, E.; Taguchi, F.; Kim, S.T.; Chang, C.N. and Iritani, Y. (1974): The immunodepressive effect of infectious bursal disease virus in chickens. Avian Dis 18: 50-57.

HUBBO, Kh.; ALOMAR, A. and FADEL, M. (2008): Prevalence of IBD Virus in some areas of Syria. Journal of AL-BAATH University. Vol. 30- No: 8- pp 241-256.

Ismail, N.; Saif, Y. and Moorhead, P. (1988): Lack of pathogenicity of five serotype 2 infectious bursal disease virusin chickens. Avian Dis. 32: 757-759.

Jackwood, D.J.; Saif, Y.M.; Moorhead, P.D. and Bishop, G. (1984): Failure of two serotype II infectious bursal disease viruses to affect the humoral immune response of turkeys. Avian Dis 28: 100- 116.

Lasher, H.N. and Shane, S.M. (1994): Infectious bursal disease. World'sPoult.Sci.,50,133-166.

Lojkic, I.Z. and Biđin B. Pokrc. (2008): Sequence Analysis of both Genome Segments of Three Croatian Infectious Bursal Disease Field Viruses. Avian Diseases Digest 3(3): e25-e25.

Lukert, P.D. and Saif, Y.M. (1997): Infectious bursal disease, p. 721-738. In B. W. Calnek, B. W. Barnes, C. W. Beard, L.R. McDougald, and Y.M. Saif (ed.), Diseases of poultry, 10th ed. Iowa State University Press, Ames.

Marquardt, W.; Johnson, R.B.; Odenwald, W.F. and Schlotthober, B.A. (1980): An indirect enzyme-linked immunosorbent assay (ELISA) for measuring antibodies in chickens infected with infectious bursal disease virus. Avian Dis. 24: 375-385.

McFerran, J.B.; McNulty, M.S.; McKillop, E.R.; Conner, T.J.; McCracken, R.M.; Collins, D.S. and Allan, G.M. (1980): Isolation and serological studies with infectious bursal disease viruses from fowl, turkey and duck: Demonstration of a second serotype. Avian Pathol 9: 395-404.

Nunoya, T.; Otaki, Y.; Tajima, M.; Hiraga, M. and Saito, T. (1992): Occurrence of acute infectious bursal disease with high mortality in Japan and pathogenicity of field isolates in SPF chicken. Avian Dis. 36: 597-609. 


\section{Assiut Vet. Med. J. Vol. 59 No. 137 April 2013}

Office international des epizooties world organis animal health. Manual of Standards for Diagnostic Tests and Vaccines. 2008

Patricia, R.; Calderón, M.G.; Aguirre, S.; Periolo, O.; Torre, J. and Mattion, N. (2006): Characterization of Infectious Bursal Disease Viruses from Argentina. Avian Diseases 50(2):245-251.

Pedro Villegas, A.; Hamoud, M.; Purvis, L.B. and Perozo, F. (2008): Infectious Bursal Disease Subunit Vaccination. Avian Diseases 52(4): 670-674.

Rodenberg, J.; Sharma, J.M.; Belzer, S.W.; Nordgren, R.M. and Naqi, S. (1994): Flow cytometric analysis of B cell and $\mathrm{T}$ cell. Subpopulations in specific-pathogen- free chickens infected with infectious bursal disease virus. Avian Dis. 38: 16-21.

Rosenberger (1989): infectious bursal disease viruses. In: Isolation and idenrification of Avian pathogens, 3rd ed (Editorial committee: Purchase, H.C., Arp L.H Domermuth, C.H.and pearson, J.E) Kendall/Hunt publishing Company, Dubuque, Iowa, PP.165-166

Sivanandan, V. and Maheswaran, S.K. (1980): Immune profile of infectious bursal disease. I. Effect of infectious bursal disease virus on peripheral blood T and B lymphocyte in chickens. Avian Dis. 24: $715-725$

Tanimura, N. and Sharma, J.M. (1997): Appearance of T cells in the bursa of Fabricius and cecal tonsils during the acute phase of infectious bursal disease virus infection in chickens. Avian Dis. 41: 638-645.

Thornton, D.T. and Pattison, M. (1975): Comparison of vaccines against IBD. J. Comp. Pathol. 85:597-610.

Tizard, I.R. (2004): Veterinary immunology (an introduction). Seventh Ed. Elsivier publishing company. Philadilphia. USA.

Wyeth, P.J. and Cullen, G.A. (1976): Maternally derived antibody effect on susceptibility of chicks to infectious bursal disease. Avian Pathol., 5: 253-260. 